\title{
EL NECESARIO USO DE LA EQUIDAD
}

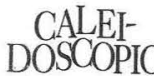

14

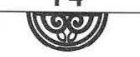

JULIO - DICIEMBRE 2003

Hugo Bernardo Márquez Elías, La justicia y la legalidad en la toma de decisiones, Aguascalientes, Supremo Tribunal de Justicia del Estado de Aguascalientes, 2003, 137 pp.

La ciencia moderna del Derecho comienza a principios del siglo XIX y, al mismo tiempo, se origina la teoría del método.

Este momento de arranque de la teoría del método está marcado por dos grandes escuelas de jurisprudencia, con su propuesta, cada una, de dirección metodológica: la Escuela Francesa de la Exégesis y la Escuela Histórica Alemana. Aunque con enormes diferencias, tienen en común el positivismo como su presupuesto filosófico. Ambas direcciones metodológicas son modelos teóricos de positivismo jurídico o iuspositivismo que, como sabemos, sólo aceptan como realidad jurídica al derecho positivo.

La Escuela de la Exégesis ha tenido una enorme influencia en la formación de los abogados. Aun ahora, a dos siglos de distancia, aunque su prestigio teórico se ha desgastado mucho, consideramos que, en buena medida, se continúa enseñando Derecho siguiendo sus pautas metodológicas. Asimismo podemos afirmar que es circular, así como se enseña, así también se entiende el Derecho por parte de los profesores, los magistrados, los jueces, los litigantes, los asesores, etc.

La Escuela de la Exégesis surge en Francia a raíz y con motivo de 
la aparición del Código Civil de Napoleón, el cual fue promulgado el 21 de marzo de 1804. "La Escuela [...] agrupó en el siglo XIX a los principales civilistas franceses"1 los cuales "se prometieron a sí mismos una ciega devoción a la obra cumbre, un respeto invulnerable, una acatamiento pleno [al Código]." ${ }^{2}$

Los fundadores de la Escuela y sus representantes en su primera etapa no son muy numerosos. En sus primeros trabajos sólo anunciaron algunos puntos esenciales de la doctrina. Sin embargo "|...| tan pronto como apareció la corriente exegética fue, por lo menos, reforzada por el espíritu y procedimientos del Gobierno Imperial, al cual no le agradaban las tendencias que se habían manifestado en la enseñanza del derecho, en las Escuelas Centrales" ${ }^{3}$, en las cuales la práctica pedagógica hacía a un lado el derecho positivo y se enseñaba

I. Bonnecase, La escucla de la Exégesis en Derecho Civil, Puebla, Ed. Cajica (Biblioteca Jurídico- Sociológica; vol. XII), 1944, p. 36.

2. Antonio Hernández Gil, Metodología de la Ciencia del Derecho. Obras completas, tomo 5, Madrid, Editorial Espasa Calpe, 1988, p. 12

Idem supra, pp. 38 y 39. el derecho natural. Este criterio del imperio napoleónico de entender el Derecho sólo como aquel producto de la legislación del Estado, empezó a propagarse e imponerse. "Los soberanos vieron en la reducción de todo el derecho a la ley el instrumento idóneo para reforzar su propia autoridad"4, señala Estrada Chávez; cómo Federico II de Prusia, uno de los monarcas codificadores, "[...] llegó a prohibir la interpretación jurídica, bajo el argumento de la racionalidad del código, por lo que en caso de duda se deberá consultar al legislador". Este mecanismo es conocido como el "principio de reserva interpretativa" y se "mantuvo por decreto orgánico en Francia aun finalizada la monarquía absoluta"

A continuación siguiendo a Bonnecase, nos referiremos a algunos de los rasgos que caracterizan a la Escuela de la Exégesis.

4 Óscar A. Estrada Chávez, "Las escuelas clásicas de interpretación y la argumentación jurídica. Primera parte. La Escuela de la Exégesis", en Revista de Investigaciones Juridicas, núm. 24, México, Escuela Libre de Derecho, 2000, p. 210.

5 Idem supra, p. 211. 


\section{Culto al texto de la ley}

Explica el historiador de esta corriente metodológica que el rasgo fundamental de la Escuela de la Exégesis es el "culto al texto de la ley" o "el culto a la ley [...]; para ella el Derecho positivo debe ser la preocupación dominante, es decir, exclusiva, del jurisconsulto, y el Derecho positivo se identifica por completo con la ley". 6

Creemos que expresiones como "La ley es la ley" o fórmulas interpretativas como "donde la ley no distingue, el hombre no tiene porque distinguir", escuchadas a profesores o leídas en textos o manuales de Derecho, son fiel reflejo de esta actitud cultual o fetichista respecto de la ley. Gleizal muestra que el modo en que se presenta, en que se enseña el Derecho moderno, es para celebrar su culto.?

II. EL PREDOMINIO DE LA INTENCIÓN DEL LEGISLADOR EN LA INTERPRETACIÓN DEL TEXTO DE LA LEY

Bonnecase, op cit., p. 141.

Cfr. Jean- Jacques Gleizal, "L'enseignement du droit dans la formation sociale française", en Pour une critique du droit, Ed. Maspero, París, 1978, p. 98.
No se permite al jurista aplicar un texto legislativo de acuerdo a las transformaciones sociales o necesidades determinadas, según la Escuela de la Exégesis "[...] un texto no vale nada por sí mismo, sino únicamente por la intención del legislador que se considera traducida por aquél; en realidad el derecho positivo se encuentra esta intención; y ésta es la que debe buscar el jurista más allá del texto."8

Así Demante escribía que: "El espíritu del legislador es para nosotros un guía tan seguro, que con frecuencia debemos hacerlo prevalecer sobre sus términos, en el sentido de que no debemos admitir todas las consecuencias autorizadas por la letra de la ley [...]"9 El 'espíritu' del legislador está sobre su propia expresión escrita. Estas expresiones nos hacen recordar a nuestros profesores que enseñaban el Derecho, o mejor dicho la ley, con el "Código en la mano", como se dice; leían un artículo y de inmediato formulaban la pregunta

Bonnecase, op cit., p.144 (subrayado en el original).

Ibid., p. 147. 
"¿Qué querrá decirnos e legislador?"

\section{Carácter profundamente ESTATISTA, PROCLAMACIÓN DE LA OMNIPOTENCIA DEL LEGISLADOR Y CREENCIA EN SU INFALIBILIDAD}

De los anteriores rasgos característicos, como son el culto al texto de la ley y la intención del legislador, se desprende su carácter estatista. "En efecto [explica Bonnecasel la doctrina de la Escuela de la Exégesis se reduce a proclamar la omnipotencia jurídica del legislador, es decir, del Estado, puesto que independientemente de nuestra voluntad, el culto extremo al texto de la ley y a la intención del legislador coloca al Derecho, de una manera absoluta, en poder del Estado". ${ }^{10}$

El Derecho, entonces, queda reducido a la ley, y ésta proviene de la voluntad del legislador, esto es, a fin de cuentas, del Estado. El Derecho es la ley del Estado y sólo la ley del Estado. El Derecho queda reducido a una de sus fuentes. Pero además se proclama prácticamente, que el legislador es

10

IGid., p. 158. infalible, de lo que se sigue que el Estado, en cuanto que legislador, también lo es.

No podemos negar que los criterios de la Escuela de la Exégesis siguen presentes en nuestro modo de entender y aplicar el Derecho. Criterios que reducen, que empobrecen, lo jurídico.

Por eso es importante y motivo de gusto que aparezca un libro como el del maestro Hugo Márquez Elías, que aporta reflexiones muy interesantes a la explicación concreta del Derecho, especialmente en lo relativo a las decisiones jurisdiccionales. El título mismo de la obra muestra ya una noción amplia del Derecho no reduciéndolo a la ley: La justicia y la legalidad en la toma de decisiones. Este texto se deriva de la investigación realizada para su tesis de maestría en Derecho presentada en la Universidad Autónoma de Aguascalientes.

Realza la importancia del libro el hecho de que su autor sea no sólo profesor de derecho procesal, sino también juez. Un juez que entiende que el derecho no se reduce a la ley, que lo jurídico tiene que ver también con la justicia. 
Para Hugo Márquez, el juez no es la "boca de la ley" como enseñan los viejos y nuevos exegetas. El juez lleva a cabo una labor de creación jurídica. Ésta se da en las decisiones que los juzgadores emiten y que constituyen "la única forma de concreción válida y real del Derecho en aquellos casos sometidos al juzgador." (p. 132).

Para el autor, las decisiones judiciales no sólo deben ser legales sino también justas. "La justicia no infringe el orden jurídico positivo, al contrario, le da sentido, porque la justicia tiene que ver con'los fines que motivan su producción" (p.133).

Para llegar a estas conclusiones, el juez hace un recorrido teórico. Su libro contiene una primera parte de sociología jurídica; una segunda de filosofía del Derecho; una tercera que analiza las corrientes de aplicación del Derecho y en la cuarta parte es donde desarrolla todo lo relativo a la aplicación del Derecho, teniendo como base algunos elementos relativos a la producción social del Derecho y a su esencia referida al ser humano.

Hugo Márquez nos propone en su libro, de manera implícita, la aplicación de la equidad o epiqueya por parte de los jueces. El autor, siguiendo las enseñanzas de González Morfín, establece que la ley es una expresión muy importante del Derecho, pero no la única; también los derechos subjetivos o facultades de las personas constituyen Derecho; y la concreción de la justicia, lo justo objetivo, como cosa o conducta debida a otro, es la esencia de lo jurídico (pp. 50 y 51).

De tal modo que el juez, al aplicar el Derecho en sus decisiones, toma la ley como normas que lo guían buscando salvaguardar derechos y le da un sentido profundo del porqué fue creada o producida, esto es, su sentido de justicia.

Al hacer esta operación que el autor nos va describiendo en su obra, el juez requiere de aplicar la equidad o epiqueya, que siguiendo a los clásicos, no viene a ser otra cosa que la "corrección de la ley".

Podría concluir señalando que la importancia del texto de Hugo Márquez estriba en que recupera para la teoría general del proceso, para el derecho procesal, en palabras de Paolo

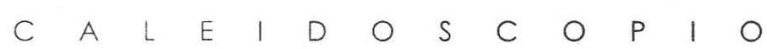


Grossi "la complejidad del jueces deberían integrarlo con universo jurídico" "', que es el uso de la razón, de la razón legalidad y justicia y que los de equidad, decimos nosotros.

2

"Pablo Grossi, "El punto y la línea. (Historia del derecho, derecho positivo en la formación del jurista de nuestro tiempo)", en Revista del Instituto de la Judicatura Federal, núm. 6, México, 2000, p. 160 . 